\title{
Traços de uma biografia "revolucionária": Flávio Koutzii por Benito Schmidt
}

Rafael Saraiva Lapuente*

\section{Caminhos, contextos e trajetórias: Flávio Koutzii como um "revolucionário" na América Latina}

Há por parte da bibliografia vinculada à Ciência Política a alegação de que o PT é a agremiação mais estudada da área (SANTIN, 2005; AMARAL, 2013), haja vista possuir uma quantidade numérica significativa de estudos com diferentes abordagens. ${ }^{1}$ Mas, se isso é relativamente consistente por parte da Ciência Política, é bem verdade que sua "irmã" - a História Política - ainda caminha com vagar sobre a história política e partidária do Brasil pósdemocratização e, mais especificamente, sobre o PT e as demais agremiações. Ainda que os historiadores frequentemente fracassem na tarefa de prever o futuro (HOBSBAWM, 2013), penso que esse contexto é temporário. E ponto chave para isso é buscar entender a trajetória daqueles que vieram a fundar e dar sustentação ao Partido dos Trabalhadores, por meio de sua militância anterior ao Colégio Sion, onde o PT foi oficialmente fundado.

Ainda que Benito Schmidt não se dedique à tarefa de entender os anos de Flávio Koutzii como membro do PT e ativo na política institucional, a biografia que o autor traça sobre uma das principais figuras da esquerda gaúcha nos ajuda a conhecer um dos membros mais ilustres da sigla no Rio Grande do Sul. ${ }^{2}$ Para isso, Benito Schmidt dividiu o trabalho em cinco capítulos, encerrando

"Doutorando em História pela PUC-RS. Bolsista CAPES.

E-mail: faelvocal@gmail.com, https://orcid.org/0000-0003-2989-109X

Anos 90, Porto Alegre, v. 25, n. 48, p. 411-418, dez. 2018 
sua biografia quando o personagem estudado retorna ao Brasil em 1984. E somente entre 1943 e 1984 resultou em um extenso trabalho de 543 páginas, fruto de sete anos de pesquisas. O autor, contudo, convoca desde o início outros pesquisadores a se debruçarem sobre o recorte posterior, chamando a atenção para o fato de que o período "em branco" do trabalho possui particularidades relevantes a serem analisadas por novos pesquisadores. Isto é, que a opção por não incluir esse período não está no fato de este ser, supostamente, menos relevante do que o estudado.

A introdução do livro chama a atenção para esse ponto, destacando que o pós-1984 "trata-se de um período riquíssimo" (SCHMIDT, 2017, p. 14), bem como dos bastidores em que chegou ao biografado e os conflitos em torno de "convencê-lo" ao recorte temporal. A introdução, sem dúvidas, é a parte do livro onde o autor provoca uma série de curiosidades e inquietudes, fazendo com que o leitor se sinta instigado a prosseguir a obra. Fugindo, assim, das introduções "burocráticas" que, por vezes, possuem os trabalhos acadêmicos.

Ter o biografado vivo, o que é pouco usual, é peça chave nisso, haja vista que a introdução vai narrando parte dos "bastidores” dos sete anos de pesquisa, em especial sobre a relação entre pesquisador e pesquisado. Ao longo do livro, Schmidt vai deixando claro, direta ou indiretamente, que Koutzii teve papel fundamental no desenvolvimento da pesquisa não apenas como entrevistado, mas sendo partícipe em todo o processo do trabalho, indicando, cedendo fontes e intermediando entrevistas. E também divergindo de Schmidt, embora o autor assinale poucas vezes no decorrer do livro os momentos em que isso ocorreu.

Essa participação de Koutzii, mais "direta”, aliada com a explícita identificação do autor com as bandeiras defendidas pelo biografado, evidentemente que deixam o leitor, como se diz popularmente, com o "pé atrás" em relação ao trabalho. Mas no decorrer do texto, à medida que Schmidt vai analisando a trajetória e, em especial, os contextos políticos nos quais Koutzii estava inserido, fica claro que não se trata de um texto chapa branca ou heroificante, comumente observado pelas biografias ditas "comerciais". 
Chama a atenção no livro também o vasto material consultado pelo autor. Schmidt, para "seguir os passos" de Koutzii, frequentou dez arquivos diferentes, localizados em Porto Alegre, Buenos Aires, Rio de Janeiro, São Paulo, assim como o acervo pessoal de Koutzii. Apesar disso, o que predomina durante o livro são as entrevistas orais. Schmidt realizou 48 delas, algumas na França, Argentina e Alemanha, com figuras que estiveram próximas de Koutzii ao longo da trajetória analisada, sendo obviamente a maioria delas com o próprio biografado. Essas entrevistas deixaram o livro com uma narrativa estimulante. Elas, aliadas com a boa escrita do autor, transformaram as densas 543 páginas em uma leitura fluida. É fácil constatar que a biografia foi escrita pensando em atingir um público maior do que aquele que possui interesses acadêmicos. ${ }^{4}$

Naquilo que concerne à organização do livro, ele foi dividido em cinco capítulos, cada um abordando uma fase diferente da vida de Koutzii. No primeiro, Benito Schmidt busca conhecer Koutzii antes de Koutzii, traçando o contexto de sua infância e adolescência no bairro Bom Fim, em Porto Alegre, bem como a estrutura familiar do biografado. Nesta, dando especial atenção a Jacob Koutzii, pai de Flávio e cuja trajetória estava vinculada ao PCB, ao judaísmo e à crítica de cinema. Nesse ponto em particular, Schmidt utilizou amplamente o livro A Tela Branca, escrito por Jacob Koutzii. A trajetória de Flávio Koutzii nesse capítulo também contempla sua vida escolar no Instituto de Educação General Flores da Cunha e no Colégio de Aplicação, dando ênfase especial às consequências de sua posição enquanto judeu e comunista quando estudava no primeiro; no segundo, Schmidt busca analisar a influência daquele ambiente para a formação política do biografado.

Como durante toda a biografia, Schmidt não se ateve apenas às atividades políticas. Esteve atento às relações pessoais de Koutzii, tanto com a família como também amorosas. Nesse capítulo, em particular, abre um fio que só terá desfecho no final do livro: o encontro entre Koutzii e Sônia Pilla, que, entre tantas idas e vindas, seria marcado por um reencontro em 1984, união que se mantém, destacando que as relações afetivas e familiares se misturavam com a ação militante em todo o período estudado. 
Essas relações pessoais também por vezes trouxeram, no decorrer do livro, tanto a distensão como a angústia. No capítulo dois, o leitor pode dar boas gargalhadas quando o autor questiona, "com alguma maldade”, se “"o Flávio jogava [futebol] bem?’. Ele respondeu o que eu pressentia: 'não”' (SCHMIDT, 2017, p. 145). Por outro lado, quando o autor se debruça sobre a prisão na Argentina, é necessária muita frieza e abstração para não se colocar no lugar de Clara Koutzii nos dias de cárcere do filho, principalmente no momento em que ela tem que optar entre visitar Flávio ou ir ao enterro do marido Jacob. O livro também possui o mérito de ressaltar por diversas passagens que, apesar das muitas dificuldades, medos, angústias e incertezas, o biografado e seus pares também abriam brechas para brincadeiras e descontrações mesmo nos momentos mais aflitos de suas respectivas trajetórias.

Depois de Benito Schmidt buscar compreender as "raízes" de Koutzii, no capítulo seguinte estuda o início da militância do biografado em Porto Alegre no PCB. Abordando o período de retorno a Porto Alegre depois de uma malsucedida tentativa de estudar em São Paulo, Schmidt destaca o papel da UFRGS na atuação política de Koutzii: "perguntei-lhe: 'e na Universidade, o que é que vocês faziam concretamente?', ao que ele respondeu sem pestanejar: "política! [risos]. Política o tempo todo"' (SCHMIDT, 2017, p. 99-100), destacando sua atuação dentro do Movimento Estudantil da UFRGS. Um dos pontos para o qual Schmidt chamou a atenção foi a vitória de Koutzii como presidente do Centro Acadêmico Franklin Delano Roosevelt, da Faculdade de Filosofia e Ciências Humanas.

Característica importante desse capítulo, que estará presente nos demais, é o fato de o autor dar ênfase especial ao contexto em que está inserido o seu personagem. Isto é, por meio da busca dos passos de Koutzii, Benito Schmidt vai traçando sempre um importante paralelo contextual, transformando o livro em uma ferramenta para compreender o Brasil dos anos 1960 - e os impactos da Ditadura Militar no Movimento Estudantil - nesse capítulo, e também as ditaduras latino-americanas pelas quais Koutzii passou em função do exílio nos capítulos seguintes. A dedicação do autor aos contextos explica o porquê de a biografia ter ficado extensa, 
mas garante uma leitura mais rica do que só "seguir os passos" de Koutzii, ressaltando as decisões tomadas pelo biografado dentro do que é chamado de campo de possibilidades.

Finaliza o capítulo 2 com a Geração de 1968 e a decisão tomada por Flávio Koutzii e membros do Partido Operário Comunista de sair do Brasil para a França clandestinamente antes que fossem presos. Assim ele sintetiza o biografado no período abordado, dizendo que "[...] Flávio vivenciou com intensidade os acontecimentos políticos do seu tempo: o movimento estudantil, o golpe de 64, os debates que sacudiram e reconfiguraram a esquerda brasileira nos primeiros anos da ditadura, a luta armada". Para Schmidt, "[...] a política, aliás, parece ter se tornado a partir de então o eixo central de sua existência, abarcando inclusive suas relações que normalmente chamaríamos de privadas, como as amizades e os amores". Por isso, compreende sua atuação política "no sentido de agir para transformar a sociedade e tomar o poder" (SCHMIDT, 2017, p. 186).

O Capítulo argentino é o título do capítulo três. Ainda que a parte mais "pesada" da biografia fosse dedicada ao capítulo seguinte e também ocorresse na Argentina, é compreensível a divisão do autor para uma parte destinada à militância de Koutzii na Argentina e, no quarto capítulo, destinando-se aos pedaços da morte no coração. Dessa forma, denota-se que existe um antes e depois na vida de Koutzii com a prisão e tortura durante a ditadura militar argentina, destacando ainda o fato de as organizações de esquerda também terem sido perseguidas nos governos de Peron e Isabelita. Embora, há de se ressaltar que o capítulo argentino abranja a atuação de Koutzii no Chile e na França.

É possível perceber, por meio do capítulo três, os artifícios dos militantes de esquerda para driblar as ditaduras latino-americanas, como a utilização de passaportes e identidades falsos, traçando, por exemplo, o trabalhoso processo empreendido por Flávio Koutzii para ir ao Uruguai e, de Montevidéu, ir de barca a Buenos Aires e, da capital argentina, se deslocar de ônibus a Santiago, para o Chile de Allende (SCHMIDT, 2017, p. 194-197). Ponto interessante do trabalho é poder observar a militância internacionalizada de Koutzii, identificando a atuação do personagem em múltiplos 
contextos, por vezes também ilustrando os choques provocados por essas diferenças.

Além disso, o livro explora a aproximação de Flávio Koutzii com a IV Internacional ainda na França e, na Argentina, sua militância no Partido Revolucionário dos Trabalhadores, na Fracción Roja, uma dissidência que teve no biografado uma das principais lideranças dos rojos, e na Liga Comunista Revolucionária.

Se o capítulo três muito lembra um "filme de ação", haja vista as estratégias lançadas pela esquerda para confrontar e burlar as ditaduras latino-americanas, em especial a argentina, no capítulo quatro, No 'coração das trevas', o autor prenuncia o que virá em um depoimento pessoal: "certas vezes, depois de realizar as entrevistas, tive que caminhar pelo parque, tomar um sorvete, ver um filme alegre a fim de recuperar certa confiança na humanidade" (SCHMIDT, 2017, p. 312). Nesse capítulo a prisão de Koutzii é analisada, tanto por meio de entrevista oral como pelo jornal $\mathrm{La}$ Razón, que definia o biografado como "o responsável pelos grupos armados na América Latina da IV Internacional” (SCHMIDT, 2017, p. 315). Junto a isso, há a análise do contexto de desaparecimentos e sequestros de membros da esquerda naquele país, ilustrando a tensão da apreensão de Koutziii nesse cenário.

As práticas de tortura são pouco analisadas em si, mas Schmidt busca compreendê-las mais como um ato organizado, estruturado e articulado do Estado argentino visando à destruição física, mas principalmente psicológica dos presos políticos. Não é à toa que o maior capítulo é o mais tenso, embora Schmidt consiga "quebrar" essa narrativa ressaltando eventuais momentos de lazer e resistências simbólicas contra o sistema prisional argentino pelos presos políticos.

O capítulo finaliza com a extensa campanha em defesa da liberdade de Flávio Koutzii, cuja presença intensa de sua mãe possui localidade central, bem como a mobilização de figuras políticas, como o deputado federal Airton Soares, intermediando sua soltura, a campanha realizada pelo Comitê Brasileiro pela Anistia e o abaixo-assinado internacional com importantes adesões da esquerda. Também foi muito destacado pelo autor o apelo embasado nas condições de saúde de Koutzii, com problemas cardíacos e a perda de 25 quilos no cárcere. Schmidt, para isso, usou ampla gama de 
materiais primários, com a cobertura que a campanha pela libertação de Flávio Koutzii possuiu, em especial na imprensa.

Para mim Paris não foi uma festa. O título do último capítulo, trecho de uma fala de Koutzii, induz o leitor a imaginar que os dramas vividos na Argentina iriam persistir na França. Mas não é o que acontece. Nesse momento, quando o biografado retorna à França, Schmidt aborda quatro fases naquele novo contexto: os primeiros contatos de Koutzii, sua relação com a psicanálise para lidar com os traumas que passou na Argentina, seu trabalho intelectual na École des Hautes Études en Sciences Sociales que resultou no livro Pedaços da morte no coração, analisando o sistema carcerário argentino e seu ingresso gradual no debate político brasileiro, posicionando-se pelo PT e participando de sua construção em Paris. Para essa fase, Schmidt foi à França entrevistar alguns integrantes da IV Internacional. Assim, buscou conhecer o período em que Koutzii esteve no país. Além dessas, Schmidt entrevistou seu psicanalista na França, que também havia saído do Brasil por motivos políticos.

A biografia termina destacando a participação, ainda que indireta, de Koutzii na fundação do PT e seu retorno em 1984. Ela é, portanto, uma biografia que estuda a atuação de Koutzii como um militante revolucionário no sentido literal da palavra. A finalização do livro conta com dois curtos textos que não são de Schmidt. O primeiro, de Guilherme Cassel, busca fazer uma breve síntese da atuação política de Koutzii como vereador e deputado estadual. Cassel, é importante destacar, foi assessor de Flávio Koutzii ${ }^{5}$, uma informação ausente do livro, mas de suma importância para aquele que não é familiarizado com a história recente da esquerda gaúcha. Uma síntese que carrega traços dessa aproximação, cujo formato é mais de um testemunho do que de uma análise, como a de Benito Schmidt.

O breve texto de Koutzii é uma síntese sobre sua vida, a experiência de participar de uma biografia em vida e um chamado. Chamado de esperança, para a reversão dos tempos sombrios decorrentes do golpe de estado de 2016. Chamado que é carregado de simbolismo, como a biografia explicita. 
Traços de uma biografia 'revolucionária': Flávio Koutzii por Benito Schmidt

\section{Notas}

${ }^{1}$ Embora, pessoalmente, eu venha defendendo que existe uma lacuna muito grande sobre os "PTs regionais", bem como das demais siglas que não possuem praticamente maiores estudos com recortes geográficos menores.

${ }^{2}$ Há de se ressaltar, entretanto, que Benito Schmidt chegou a redigir um livro chamado História e memórias do PT gaúcho (1978-1988), onde aborda esse processo inicial do PT. A obra, contudo, nunca foi publicada. O autor desta resenha teve acesso ao "borrão" do livro, cedida por Schmidt, ao qual agradeço por isso.

${ }^{3}$ Refiro-me a biografias escritas normalmente por pesquisadores "independentes" e jornalistas, cujo apelo comercial descompromissa de maior aprofundamento e de rigores teóricos e metodológicos inerentes à pesquisa acadêmica.

${ }^{4}$ De fácil constatação foi a positiva recepção da obra por parte de diversos militantes do PT e da esquerda do Rio Grande do Sul, observando-se que, no dia do lançamento do livro, boa parte dela esteve reunida. No local do lançamento, ocorrido no Santander Cultural, um número considerável do público ficou do lado de fora da sala, impedido de assistir à fala de Koutzii, pela superlotação.

${ }^{5}$ Koutzii, inclusive, atribuiu, em entrevista, a sua atuação parlamentar destacada pela escolha de sua equipe. Perguntado sobre ela, disse: "Era o Guilherme Cassel e o Paulo Muzell, esses dois praticamente como os caras que ajudavam a pensar e a escrever essas coisas". Entrevista de Flávio Koutzii para César Filomena. Disponível em: <https://www.dropbox.com/sh/3cfi97dfs93zfic/AADGZ5A1D pcfdN9KZVtc0E0ya?n=421284457\&oref=e >. Acesso em: 16 nov. 2017.

\section{Referências}

AMARAL, Oswaldo E. do. As transformações nas organizações internas do Partido dos Trabalhadores (1995-2010). São Paulo: Alameda, 2013.

ENTREVISTA de Flávio Koutzii para César Filomena. Disponível em: <https:// www.dropbox.com/sh/3cfi97dfs93zfic/AADGZ5A1DpcfdN9KZVtc0E0ya?n $=421284457$ \&oref $=\mathrm{e}>$. Acesso em: 16 nov. 2017.

HOBSBAWM, Eric. Sobre História. São Paulo: Companhia das Letras, 2013.

SANTIN, Ricardo. Construção de um partido político: a trajetória e a estabilidade política do PP gaúcho. Porto Alegre: Editora Berthier, 2005.

SCHMIDT, Benito Bisso. Flávio Koutzii: biografia de um militante revolucionário. Porto Alegre: Libretos, 2017.

Recebido em: 18/01/2018

Aprovado em: 16/06/2018

Anos 90, Porto Alegre, v. 25, n. 48, p. 411-418, dez. 2018 